\title{
Cathode Luminescence Spectroscopy of Gold Nanoparticle Catalyst in Gas Environments
}

Takayuki Tanaka $^{1,2}$, Naoki Yamamoto ${ }^{1,2}$, Kunio Takayanagi ${ }^{1,2}$

1. Department of Physics, Tokyo Institute of Technology, 2-12-1-H-51, Oh-okayama, Meguro-ku, Tokyo 152-8551, Japan

2. Core Research for Evolutional Science and Technology (CREST), Japan Science and Technology Agency, K's Gobancho, 7, Gobancho, Chiyoda-ku, Tokyo 102-0076, Japan

Gold nanoparticle on $\mathrm{TiO}_{2}\left(\mathrm{Au} / \mathrm{TiO}_{2}\right)$ [1-5] and $\mathrm{Cu}$-doped $\mathrm{TiO}_{2}$ [6] are promising for application to low temperature $\mathrm{CO}$ oxidation $\left(2 \mathrm{CO}+\mathrm{O}_{2} \rightarrow 2 \mathrm{CO}_{2}\right)$ catalyst [1-5] and visible light-sensitive photocatalyst [6], respectively. It is proposed that their catalyses are excited by negatively charged $\mathrm{O}_{2}$ molecule $\left(\mathrm{O}_{2}^{-}\right)$ [1-6], which is proposed to be generated by Au- $\mathrm{O}_{2}-\mathrm{Ti}$ co-bonding [4], interstitial $\mathrm{Ti}$ ion [3, 7] and $\mathrm{Cu}$ dopant [6]. We studied the effect of adsorbed $\mathrm{O}_{2}\left(\mathrm{O}_{2}^{-}\right)$in $\mathrm{Au} / \mathrm{TiO}_{2}$ catalyst, from the change of electronic states by gas adsorption.

Specimens of $\mathrm{Au} / \mathrm{TiO}_{2}$ were prepared in a vacuum chamber. The $\mathrm{TiO}_{2}$ (rutile) crystals were annealed at $1170 \mathrm{~K}$ for 1 hour and gold was deposited subsequently on the $\mathrm{TiO}_{2}$ at room temperature to form nanoparticles. The $\mathrm{Au} / \mathrm{TiO}_{2}$ specimen was mounted on a gas-injection holder for experiments of bright field scanning transmission electron microscopy (BF-STEM) and cathode luminescence (CL).

The $\mathrm{Au} / \mathrm{TiO}_{2}$ specimen was observed by STEM. Figure 1 (a) shows a typical BF-STEM image of $\mathrm{Au} / \mathrm{TiO}_{2}$. Figure 1 (b) shows the corresponding spectrum map of CL (CL map) at $404 \mathrm{~nm}$. The CL map was drawn from CL spectra, which were simultaneously acquired with the STEM image of Fig. 1 (a). The CL map is colored by the CL intensity at $404 \mathrm{~nm}$. As the thickness of $\mathrm{TiO}_{2}$ increased, intensity of CL spectrum was inclined to increase in Fig. 1 (b). The peak wavelength depended on the local position of $\mathrm{Au} / \mathrm{TiO}_{2}$. In the $\mathrm{Au} / \mathrm{TiO}_{2}$ region of Fig. 1 (a), the peak wavelengths were $400 \sim 490 \mathrm{~nm}$. The wavelength of $\lambda \sim 410 \mathrm{~nm}$ corresponds to band gap energy of $\mathrm{TiO}_{2}(3.0 \mathrm{eV})$.

Figure 2 (a) showed a "mean CL spectrum", which was acquired in condition of no gas exposure. The "mean CL spectrum" was averaged in a region of an $\mathrm{Au} / \mathrm{TiO}_{2}$ specimen. The peak wavelength of the mean CL spectrum was $393 \mathrm{~nm}$. The mean CL spectrum changed by $\mathrm{O}_{2}$ exposure of $1 \times 10^{-4} \mathrm{~Pa}$. The change from the spectrum of Fig. 2 (a) to that of the $\mathrm{O}_{2}$ exposure, called " $\mathrm{O}_{2}$ spectrum" hereafter, was shown by purple curve in Fig. 2 (b). The $\mathrm{O}_{2}$ spectrum showed new broad peaks, which ranged from 350 $\sim 390 \mathrm{~nm}$. The broad peaks included signals below $\lambda=410 \mathrm{~nm}$, correspondent to band gap energy of $\mathrm{TiO}_{2}$. On the other hand, the mean CL spectra did not change by $\mathrm{CO}$ exposure of $1 \times 10^{-4} \mathrm{~Pa}$. The CO spectrum of $1 \times 10^{-4} \mathrm{~Pa}$, defined as the change from the spectrum of Fig. 2 (a), did not have new peaks, as shown by green curve in Fig. 2 (b). Spectrum of co-exposure of $\mathrm{CO}$ and $\mathrm{O}_{2}$ at each partial pressure of $1 \times 10^{-4} \mathrm{~Pa}$, as shown by red curve in Fig. 2 (b), was similar to the $\mathrm{O}_{2}$ spectrum of $1 \times 10^{-4} \mathrm{~Pa}$. It is found that the changes of mean CL spectra by gas exposure depend on partial pressure of $\mathrm{O}_{2}$. The new peaks below $\lambda=410 \mathrm{~nm}$ by $\mathrm{O}_{2}$ exposure are thought to be the resonance state of $\mathrm{O}_{2}$ adsorption $\left(\mathrm{O}_{2}^{-}\right)$. The change by $\mathrm{CO}$ exposure of $1 \times 10^{-4} \mathrm{~Pa}$ was not almost detected.

References:

[1] M. Haruta, et al., J. Catal. 144 (1999) 175.

[2] T. Tanaka, et al., Surf. Sci. 604 (2010) L75.

[3] T. Tanaka et al., Microsc. Microanal. 18 (Suppl. 2), 1300 (2012).

[4] Z.-P. Liu, X.-Q. Gong, J. Kohanoff, C. Sanchez, and P. Hu, Phys. Rev. Lett. 91 (2003) 266102. 
[5] M. Okumura, J. M. Coronado, J. Soria, M. Haruta, and J. C. Conesa, J. Catal. 203 (2001) 168.

[6] H. Irie et al, J. Phys. Chem. C 113, 10761.

[7] S. Wendt et al., Science 320 (2008) 1755.

(a)

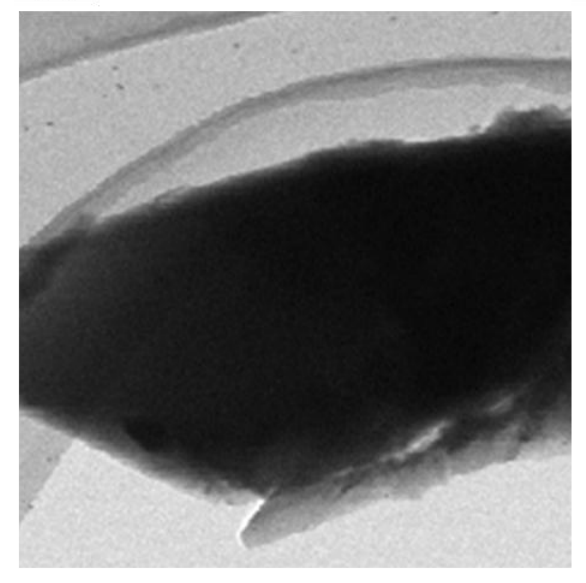

(b)

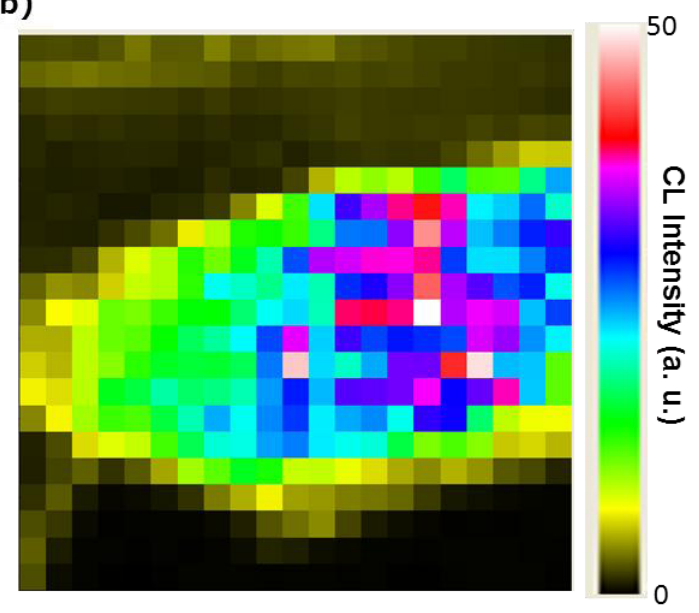

Figure 1. (a) BF-STEM image of $\mathrm{Au} / \mathrm{TiO}_{2}$ specimen $(940 \mathrm{~nm} \times 940 \mathrm{~nm})$ and (b) the corresponding CL Map at $404 \mathrm{~nm}$. The CL map is colored by the CL intensity at $404 \mathrm{~nm}$. As the CL intensity increases, the color changes from black to white.

(a)

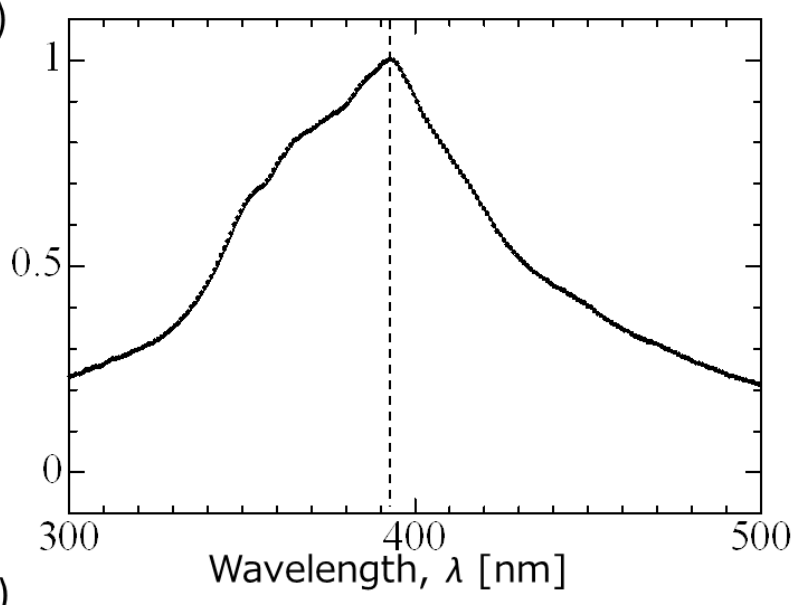

(b)

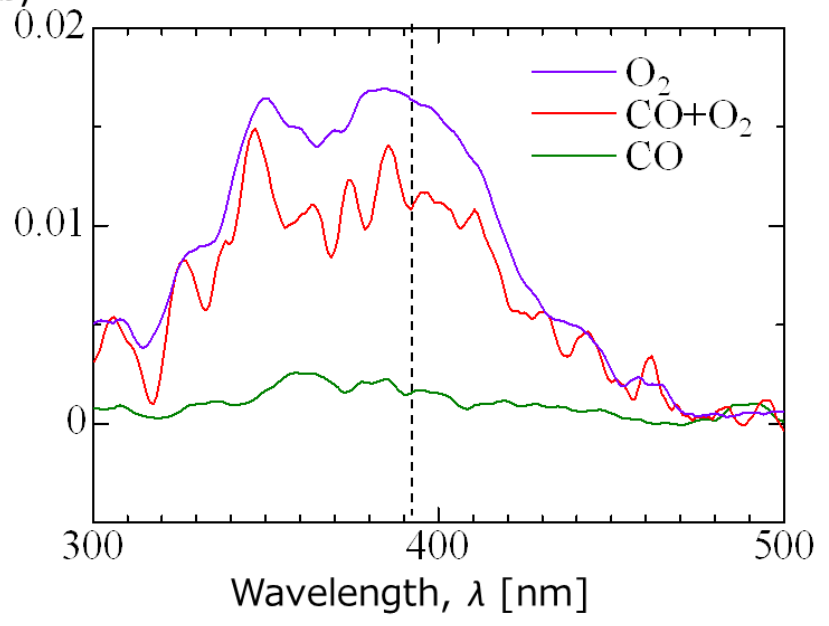

Figure 2. (a) Mean CL spectrum acquired by no gas exposure. Mean CL spectrum is averaged in a region of $\mathrm{Au} / \mathrm{TiO}_{2}$. (b) Change of mean spectrum from (a) by $\mathrm{O}_{2}$ exposure of $1 \times 10^{-4} \mathrm{~Pa}$, drawn by purple curve, $\mathrm{CO}$ exposure of $1 \times 10^{-4} \mathrm{~Pa}$ by green curve and co-exposure of $\mathrm{CO}$ and $\mathrm{O}_{2}$ at each partial pressure of $1 \times 10^{-4} \mathrm{~Pa}$ by red curve, respectively. 